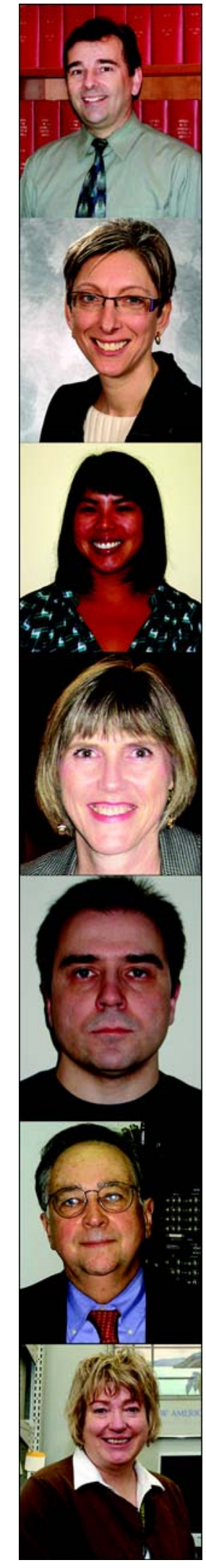

Robert L. Folmer, PhD; Gabrielle H. Saunders, PhD; Serena M. Dann, AuD; Susan E. Griest, MPH; Edward Porsov, MS; Stephen A. Fausti, PhD; Marjorie R. Leek, PhD

\section{Computer-based hearing loss prevention education program for Veterans and military personnel}

\section{INTRODUCTION}

According to the Veterans Benefits Administration, more than 672,000 Veterans were service-connected for hearing loss and more than 744,000 Veterans were service-connected for tinnitus as of fiscal year 2010 [1]. Hearing loss and tinnitus are the most prevalent disabilities experienced by Veterans who served during peacetime, Operation Iraqi Freedom/Operation Enduring Freedom, World War II, and the Korean war. In fiscal year 2010, the Department of Veterans Affairs (VA) provided 561,212 hearing aids at an estimated cost of \$196.7 million and audiological services to Veterans at a cost of $\$ 227.4$ million. ${ }^{*}$ Therefore, hearing loss and tinnitus prevention should be a priority for the VA. At least one type of hearing loss-noiseinduced hearing loss (NIHL)—can be prevented if appropriate protective strategies are implemented.

Citing the high prevalences of hearing loss and tinnitus among Veterans, Fausti et al. concluded that programs aimed at preventing hearing loss should include education concerning the effects of both occupational and recreational noise exposures, as well as counseling on the hearing protection methods available to individuals at risk for NIHL [2]. Subsequently, authors Saunders and Griest worked with a video production company (Craftmaster Productions; Portland, Oregon) to implement this recommendation by developing a computer-based hearing loss prevention program (HLPP) for Veterans that could be accessed by patients in VA medical clinics [3].

\section{HEARING LOSS PREVENTION PROGRAM}

The HLPP uses the constructs described in the Health Belief Model (HBM) developed by Rosenstock [4] to explain individual differences in decisions to practice particular health behaviors. To varying degrees, the HBM predicts health-related behaviors, such as prenatal care visits [5],

\footnotetext{
* Dennis, Kyle C. (Audiology and Speech Pathology National Program Office, VA, Washington, DC). Email to: Gabrielle Saunders. 2011 Nov 22.
} 
breast cancer self-examination [6], continued enrollment in diabetes-related pharmaceutical services [7], and hepatitis B vaccination [8]. The principles outlined in the HBM were described by Folmer et al. [9, p. 12] as follows:

1. "Perceived Susceptibility: The feeling of being vulnerable to a condition and the extent to which the individual believes he/she is at risk of acquiring the condition.

2. Perceived Severity: Belief in the seriousness of the consequences incurred if [a person is] affected by the condition both medically (e.g. death, disability, pain) and socially (e.g. effects on family life, personal relations).

3. Perceived Benefits: The belief that intervention will result in positive benefits.

4. Perceived Barriers: The barriers an individual believes he/she needs to overcome in order to effectively conduct some form of intervention. This includes costs, negative side effects, social stigma, and time needed for implementation.

5. Perceived Efficacy: Belief the individual has that he/she can successfully use the intervention.

6. Cue to Action: A cue that prompts an individual to take action. This could be internal, such as symptoms of a health problem, or external, such as media communications, interpersonal communications, or information from healthcare providers.”

One goal of the HLPP is to increase participants' knowledge about auditory system damage that can be caused by loud sounds and methods of hearing protection, which in turn would change participants' understanding and attitudes about noise exposure and hearing protection. The ultimate goal of this, and all HLPPs, is to motivate participants to change their behaviors in noisy situations so they implement appropriate hearing protection strategies. Most Veterans were exposed to loud sounds during their military service. Additional unprotected noise exposure will contribute to hearing loss in this population. Indeed, evidence exists that ears with prior noise damage age differently than those without significant noise exposure. Specifically, hearing loss progresses more quickly in noise- exposed ears than in ears not exposed to noise and loud sounds cause greater damage to alreadyexposed ears [10]. Given this knowledge, it follows that Veterans, whose ears were probably exposed to high levels of noise during military service, must now protect their ears to avoid exacerbating cochlear damage and thus accelerating the progression of age-related hearing loss. The VA does not provide a hearing loss prevention education program for Veterans, although such instruction would be beneficial.

The HLPP is a self-administered, multimedia, computer-based program developed for Veterans and designed for use in an outpatient clinic or in a communal area of a hospital. It has the following specifications (as described by Folmer et al. [9, p. 15]):

- The HLPP “is modular in design so that users can select topics in which they are interested. According to the learning theory, adults learn best when information is practical and relates meaningfully to their lives [11].

- The program is self-administered. It does not require a professional to supervise or train users.

- The program is low maintenance and does not require upkeep from healthcare professionals. The software can be modified to implement changes to the program's content.

- The presentation volume level is adjustable to accommodate hearing-impaired individuals, since many Veterans [already] have [some] hearing loss.

- The visual components of the program are clearly visible [e.g., large text fonts are used] in accordance with published guidelines [12].”

- All written content of the program has a reading level of between grades 5 and 8 so that it is understandable to a large proportion of the adult population [13].

In 2007, authors Leek and Fausti received a Joint Incentive Fund (JIF) award to develop a stand-alone hearing loss prevention education program for Veterans and military personnel. JIF is a VA and Department of Defense (DOD) collaborative program that is designed to facilitate the mutually beneficial coordination, use, or exchange of health care resources, with the goal of improving the access to and quality 
and cost-effectiveness of the healthcare provided to beneficiaries of both departments. Leek and Fausti worked with the other authors of this article to redesign and adapt the HLPP for both Veterans and Active Duty military personnel. The new version of the JIF HLPP includes the following elements, which were described by Folmer et al. [9, p. 12]:

- A sound-attenuated enclosure-called the Hearing Education Center (HEC) - “(6 feet wide by 8 feet long by 8 feet high) in which one participant at a time interacts with the program (Figure 1).

- "On a booth exterior wall, a 40" flat screen LCD [liquid crystal display] displays silent video clips and text describing [what] the booth [is] and activities available inside” (see Figure 1).

- One exterior wall of the booth features a life-size human outer ear that is made of flexible plastic and attached internally to a sound level meter (Figure 2). When participants insert an iPod or MP3 ear bud into the ear, the digital display shows the intensity of the music in decibels sound pressure level (SPL). Text in the wall

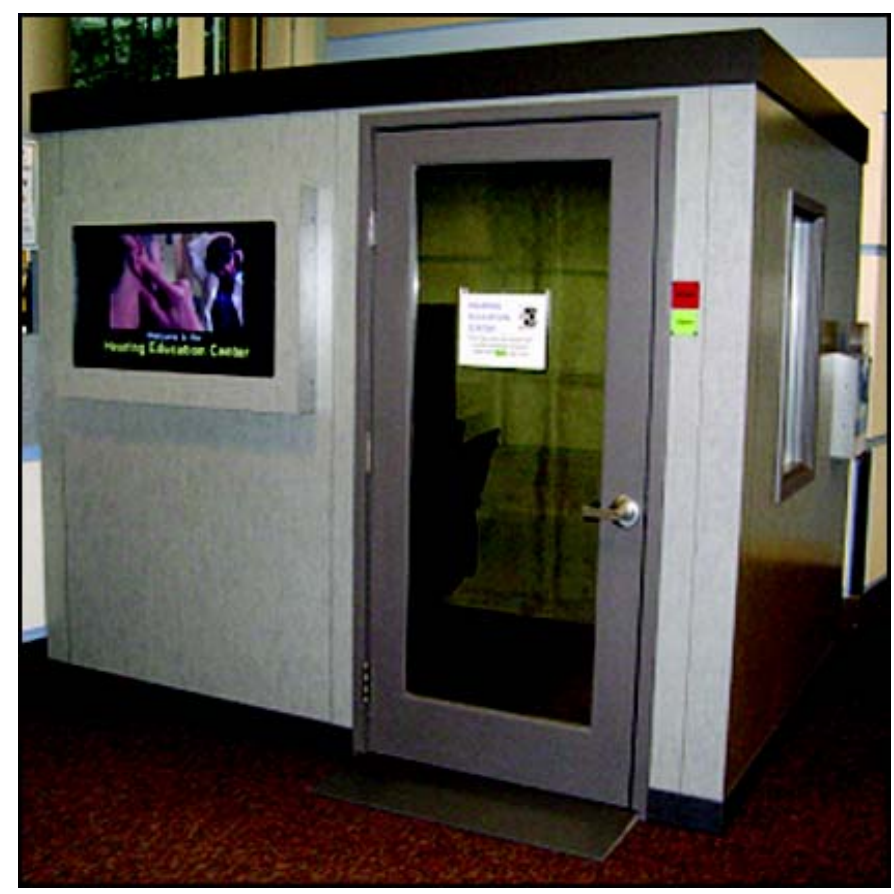

Figure 1.

Hearing Education Center at Portland Department of Veterans Affairs Medical Center.

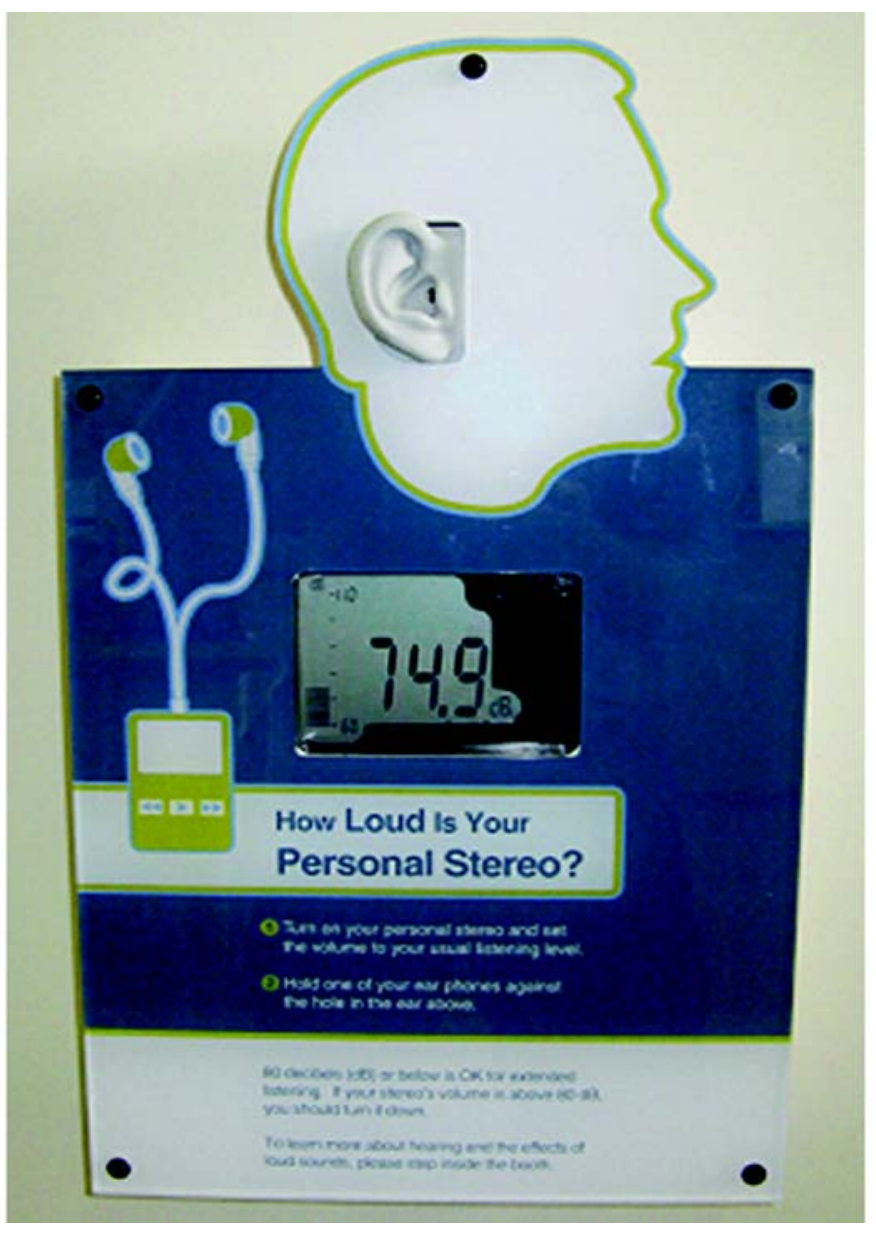

Figure 2.

"Check your iPod" module on booth exterior wall.

panel instructs participants that $80 \mathrm{~dB}$ SPL or lower is a safe level for extended listening.

- The inside of the enclosure (Figure 3) has a work station with a computer touch screen monitor, a pair of high-quality headphones, a chair, and a printer that is inside a locked cabinet. The personal computer that powers the touch screen is also inside the locked cabinet and not accessible to users of the program. The touch screen allows participants to select among a variety of activities, and the printer allows them to print informational handouts and test results.

- On-screen video and audio instructions show participants how to place headphones on their ears correctly and to set the volume of the program at a comfortable listening level. 


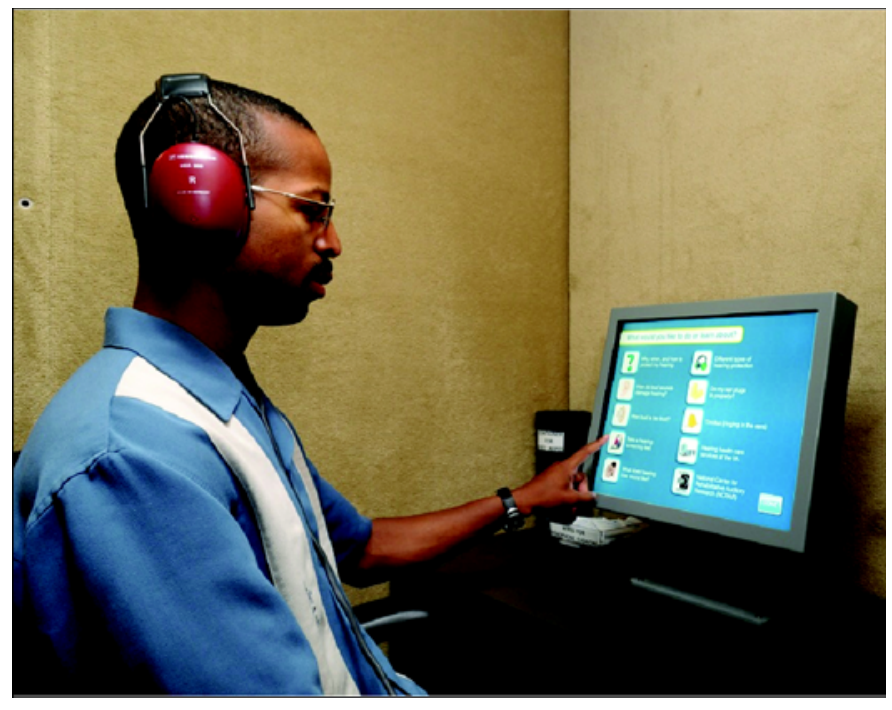

Figure 3.

Booth interior showing computer touch screen interface and headphones.

Effective health communication programs should be easily understandable, user-friendly, and culturally relevant [14]. For this reason, we worked with the Oregon Museum of Science and Industry (OMSI) in Portland, which designed and built the sound-attenuated booths and the "check your iPod" module and provided the graphical user interface and computer programs that deliver the audio and visual content. OMSI was selected to provide these program elements because the museum has a great deal of experience designing and building interactive exhibits for public use. Among its projects, OMSI built the "Dangerous Decibels" hearing conservation exhibit that was on display at the museum from 2002 to 2010 (www.dangerousdecibels.org). We also worked with a video production company (Craftmaster Productions) to develop new program content specifically for Active Duty soldiers and to produce a 3 min informational video on tinnitus. In versions of the program designed for Army personnel, content includes examples of noise exposure and hearing loss prevention strategies related to military training, combat, weapons fire, military vehicles, and recreational and occupational activities. Key messages include the importance of hearing for soldiers' readiness for duty, ability to carry out mis- sions, and survival. By contrast, the version of the program designed for Veterans focuses more on quality of life and interpersonal communication difficulties that people with hearing loss experience, along with strategies for managing those difficulties.

After participants enter the booth, put on headphones, and set the volume of the program to a comfortable listening level, they are asked to answer the following questions via the touch screen interface:

- Have you used this program in this booth before? (yes or no).

- I am a Veteran (yes or no).

- My age (<18, 18-29, 30-39, 40-49, 50-59, 60$69,70-79$, or $80+)$.

- I am (male or female).

- During the last year, I (check all that apply):

- Have been around loud sounds that made my ears hurt or "ring."

- Used power tools or loud machinery.

- Fired a gun.

- Listened to loud music.

- I wear ear plugs or ear muffs (hearing protectors) when I am around loud sounds (always, sometimes, never).

A 2 min video then introduces the program and provides some basic information about hearing, noise exposure, and hearing protection (Video). When the introductory video concludes, the program shifts to the main menu screen (Figure 4). Participants may then select from among the following activities:

- Module 1: Learn why, when, and how to protect hearing. This 4 min video provides an overview of basic information related to hearing loss prevention.

- Module 2: How do loud sounds damage hearing? This 2 min video contains 3-dimensional animations that show how hearing normally works and how loud sounds can damage inner ear structures. The animated segment was taken (with permission) from the 2004 video "Sound Advice" distributed by the Naval Medical Education and Training Center (Bethesda, Maryland). 


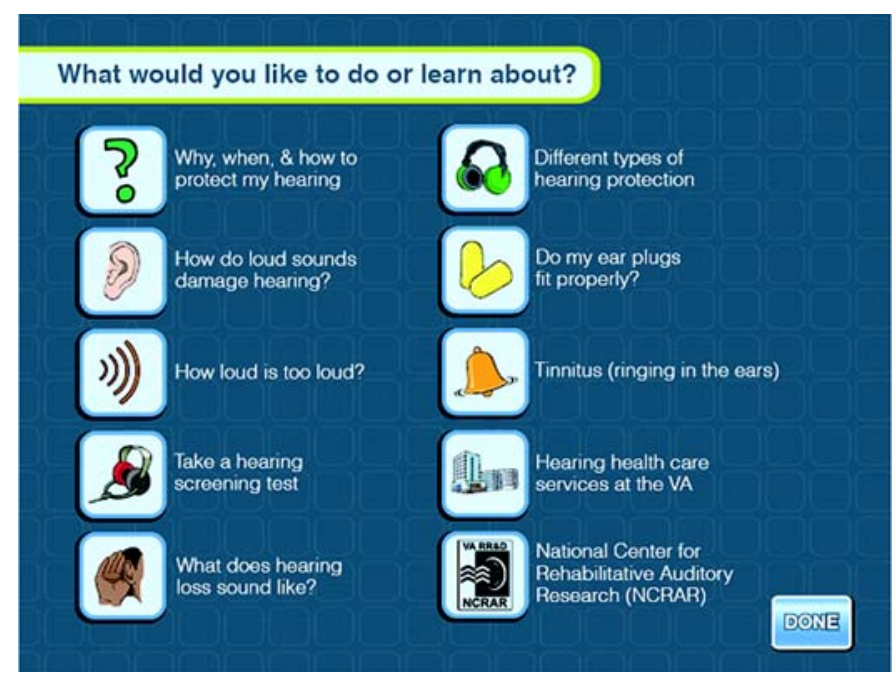

Figure 4.

Main menu screen.

- Module 3: How loud is too loud? First, a brief video describes how sound intensity is measured and shows examples of typical sound levels in the environment. The screen then shifts to an interactive activity that allows participants to select different listening situations of interest, including occupational and recreational settings. Participants are shown the typical sound levels for each example, safe exposure times, and appropriate hearing protection strategies to use in these situations.

- Module 4: Take a hearing screening test. Participants can conduct a self-administered hearing screening of high-frequency pure tones from 20 to $60 \mathrm{~dB}$ HL (hearing level). The Quick Test screens $4000 \mathrm{~Hz}$ (takes $2 \mathrm{~min}$ or less); a more complete test screens 3000, 4000, and $6000 \mathrm{~Hz}$ (takes 6 min or less). Participants have the option to print out test results and recommendations.

- Module 5: What does hearing loss sound like? This module begins with a brief video that demonstrates how hearing loss adversely affects communication abilities and social interactions. The screen then shifts to an interactive activity that allows participants to select from among different simulations of hearing impairment in a variety of listening situations, including speech, music, and environmental sounds. A 2 min segment from a "Flintstones" cartoon (with the audio portion filtered) demonstrates the progression from normal hearing to mild, moderate, and severe hearing loss. All these hearing loss simulations were produced by Sensimetrics Corporation (Malden, Massachusetts).

- Module 6: Learn about different types of hearing protection. Interactive screens provide information about different types of hearing protectors, with examples of what each type is most suited for. Participants have the option to print out information sheets to take with them. Brief videos show participants how to insert/fit and care for the protectors.

- Module 7: Do my ear plugs fit properly? This interactive module allows participants to evaluate the fit of their own ear plugs. The module is based on the National Institute for Occupational Safety and Health (NIOSH) "Quick Fit Test" that determines whether users are receiving at least $15 \mathrm{~dB}$ of attenuation from their ear plugs. The NIOSH test is available online at http:// www.cdc.gov/niosh/mining/topics/hearingloss/ quickfitweb.htm.

- Module 8: Learn about tinnitus (ringing in the ears). This 3 min video provides basic information about tinnitus, including strategies that will help sufferers successfully manage the condition.

- Module 9: Learn about hearing healthcare services at [booth location]. Two screens of basic information (including telephone numbers, addresses, Web sites, and clinic hours) describe hearing healthcare services available at each facility where a booth is installed. Participants have the option to print out an information sheet to take with them.

- Module 10: Learn about the National Center for Rehabilitative Auditory Research (NCRAR). Two screens briefly describe the NCRAR, the only Center of Excellence in the VA system dedicated to auditory research.

It would take participants $30-40$ min to review all of the material in these 10 modules. However, 
participants can choose to interact with fewer modules if their time is limited.

Initial installations of HECs are at the Portland (Oregon) VA Medical Center; Joint Base LewisMcChord, Washington; and Fort Stewart, Georgia. Access to the booths is free of charge and open to the public and does not require an appointment. The booths are located in relatively high-traffic areas, preferably where the target population may be spending some “down” time. For example, at the Portland VA Medical Center, the booth is located in a multiclinic waiting area where outpatients wait to be called for their medical appointments. At Fort Lewis, the HEC is located in the front corridor of Waller Hall, a large welcome/processing center that also contains Starbucks coffee and Subway sandwich shops. The booth at Fort Stewart is located near a food court and a large furniture/appliance store on base. The external video screen on the booth, as well as posted signs, encourage potential participants to enter the booth and use the program inside. No identifiable information is requested of program users, so there are no HIPAA [Health Insurance Portability and Accountability Act of 1996] or institutional review board issues regarding participant privacy.

\section{DATA COLLECTED FROM PROGRAM PAR- TICIPANTS AT PORTLAND VA MEDICAL CENTER}

At the start of the program, participants are presented with a series of questions regarding demographics, noise exposure, and use of hearing protection, responses to which are stored by the computer for later examination. Responding to questions in the program is voluntary; therefore, participants may skip (not answer) any questions if they so choose. After the preliminary questions are answered or skipped, participants watch an introductory video that provides information about hearing, noise exposure, and hearing protection. After the video, participants select among the 10 modules shown in Figure 4. When participants elect to exit the program, three additional questions are pre- sented onscreen that ask about their experience in the HEC.

Table 1 shows the sex and age distribution for participants who visited the booth at the Portland VA Medical Center between July 1, 2010 (the day it was installed) and December 1, 2011. The fact that twice as many men versus women used the program is not surprising, given its location in a VA facility.

Table 2 shows distributions of responses to the following questions: "I am [male/female]," "Have you used this program in this booth before?" and "I am a Veteran [yes/no].” A large percentage (93.4\%) of respondents reported that it was their first time using the program. Of the 2,068 individuals whose data are shown in Table 2, 1,218 were male Veterans, 150 were female Veterans, 175 were male nonVeterans, and 525 were female non-Veterans.

Table 3 contains responses to questions about participants' noise exposure during the previous year.

Table 1.

Age and sex distribution of participants.

\begin{tabular}{cccc}
\hline Age $(\mathbf{y r})$ & Male & Female & Total, $\boldsymbol{n}(\mathbf{\%})$ \\
\hline$<18$ & 29 & 31 & $60(3)$ \\
$18-29$ & 59 & 49 & $108(5)$ \\
$30-39$ & 78 & 50 & $128(6)$ \\
$40-49$ & 171 & 114 & $285(14)$ \\
$50-59$ & 295 & 227 & $522(25)$ \\
$60-69$ & 543 & 156 & $699(33)$ \\
$70-79$ & 163 & 58 & $221(11)$ \\
$80+$ & 56 & 13 & $69(3)$ \\
\hline Total, $n(\%)$ & $1,394(67)$ & $698(33)$ & 2,092 \\
\hline \hline
\end{tabular}

Table 2.

Participant responses ( $n$ [\%] or $n$ ) to onscreen questions.

\begin{tabular}{lc}
\hline \multicolumn{1}{c}{ Question } & Response \\
\hline Have you used this program in this booth before? \\
Yes & $137(6.6)$ \\
No & $1,936(93.4)$ \\
Veteran Status and Sex & \\
Veteran & 1,368 \\
Male & 1,218 \\
Female & 150 \\
Non-Veteran & 700 \\
Male & 175 \\
Female & 525 \\
\hline \hline
\end{tabular}


Table 3.

Participant responses ( $n$ [\%]) to question about their exposure to loud sounds.

\begin{tabular}{|c|c|c|c|c|c|c|}
\hline \multirow{2}{*}{ Question } & \multicolumn{3}{|c|}{ Yes } & \multicolumn{3}{|c|}{ No } \\
\hline & Male & Female & Combined & Male & Female & Combined \\
\hline \multicolumn{7}{|c|}{ During Last Year, I (Check All that Apply) } \\
\hline Used Power Tools or Loud Machinery & 725 (80.9) & $171(19.1)$ & $896(44.0)$ & $646(56.7)$ & 493 (43.3) & $1,139(56.0)$ \\
\hline Fired a Gun & $428(83.6)$ & $84(16.4)$ & $512(25.2)$ & $944(62.0)$ & $579(38.0)$ & $1,523(74.8)$ \\
\hline
\end{tabular}

These questions were asked before any educational content was presented. Participants were able to select more than one source of loud noise exposure. In the general population, males are more likely than females to participate in noisy activities, such as firing guns or using power tools. Data collected in the Portland HEC agrees with this trend: 512 (25\%) of the total respondents $(2,035)$ fired a gun during the previous year; the male:female ratio of shooters was $>5: 1$, whereas the sex ratio for all booth participants was 2:1. The male:female ratio for respondents who used power tools or loud machinery during the last year was $>4: 1$. This tendency for more males than females to engage in noisy activities is one of the reasons that male hearing sensitivity declines faster than that of age-comparable females.

Table 4 contains information related to participants' use of hearing protection devices (HPDs) when they are around loud sounds. This question was also asked before any educational content was presented. Only 13.6 percent of all respondents always wear HPDs when they are around loud sounds, a very low percentage that probably contributes to the prevalence of NIHL in this population. A relatively high percentage (48\%) of females answered "Never" to this question (compared with

Table 4.

Participant responses ( $n[\%]$ ) to question about hearing protection.

\begin{tabular}{lccr}
\hline \multicolumn{1}{c}{ Question } & \multicolumn{1}{c}{ Male } & Female & \multicolumn{1}{c}{ Combined } \\
\multicolumn{4}{l}{ I Wear Ear Plugs or Ear Muffs (Hearing Protectors) } \\
\multicolumn{4}{c}{ When Around Loud Sounds } \\
Always & $223(16.6)$ & $46(7.3)$ & $269(13.6)$ \\
Sometimes & $719(53.5)$ & $281(44.3)$ & $1,000(50.6)$ \\
Never & $401(29.9)$ & $307(48.4)$ & $708(35.8)$ \\
\hline \hline
\end{tabular}

$30 \%$ of males who answered "Never"). Some female participants possibly answered "Never" because they are seldom, if ever, exposed to extremely loud sounds, such as machinery, power tools, or gun fire.

Combining participants' responses to some questions in Tables 3 and $\mathbf{4}$ yielded the results shown in Table 5. Overall, these results indicate fairly low use of HPDs, which is typical in the general population. Particularly alarming is that only 19 percent of individuals always wore hearing protection when firing a gun, because gun fire is so loud that a single exposure without hearing protection can cause damage to inner ear structures, resulting in hearing loss and/or tinnitus. Also disappointing is the finding that only 14.6 percent of respondents always wore hearing protection when using power tools or loud machinery. These results illustrate the need for increased hearing loss prevention efforts among Veterans and the general public.

Table 6 contains participants' responses to three questions that appear on screen when participants elect to exit the session. Of more than 2,000 total program participants at the Portland VA Medical Center, approximately 50 percent of them took the time to

Table 5.

Combined responses ( $n[\%])$ to questions about noise exposure and use of hearing protection.

\begin{tabular}{llcc}
\hline \multicolumn{1}{c}{ Question } & Always & Sometimes & Never \\
\hline $\begin{array}{l}\text { During the Last Year, I Fired a } \\
\text { Gun and Wore Hearing Pro- }\end{array}$ & & & \\
tection & & & \\
During the Last Year, I Used & $128(14.6)$ & $531(60.5)$ & $219(24.9)$ \\
Power Tools or Loud Machin- & & & \\
ery and Wore Hearing Protec- & & & \\
tion & & & \\
\hline \hline
\end{tabular}


Table 6.

Participant responses ( $n[\%])$ to three questions presented onscreen at end of each session.

\begin{tabular}{lcc}
\hline \multicolumn{1}{c}{ Question } & Yes & No \\
\hline $\begin{array}{l}\text { Do You Think this Program is a } \\
\text { Good Way to Provide Informa- }\end{array}$ & $997(98.4)$ & $16(1.6)$ \\
tion about Hearing Protection? & & \\
Will You Now Be More Likely to & $920(91.7)$ & $83(8.3)$ \\
Protect Your Hearing from Loud & \\
Sounds? & \\
Would You Recommend this Pro- & $978(97.4)$ & $26(2.6)$ \\
gram to Your Family, Friends, or & & \\
Coworkers? & & \\
\hline \hline
\end{tabular}

answer these three questions. An overwhelming majority (98\%) of responders thought the program was a good way to provide information about hearing protection and a similarly large percentage (97\%) would recommend the program to family, friends, or coworkers. We were pleased to see that 92 percent of these responders would "now be more likely to protect" their hearing from loud sounds. Although actual implementation of hearing protection strategies is a better measure of compliance (or behavioral change), the participants' stated willingness to do so is encouraging.

Data from HECs at the two Army bases will be analyzed after a greater number of participants utilize the programs there.

\section{DISCUSSION}

According to Folmer et al. [9, p. 16], “previous studies of hearing loss prevention education programs found that it is relatively easy to increase participants' knowledge about how hearing works, how hearing is damaged by loud sounds, and how and when to employ protective strategies. However, it is more difficult to inspire participants to change existing behaviors and to implement new strategies in real-life situations" [15]. Clearly, our sample of individuals found the program to be enjoyable and useful. In fact, 137 individuals used the booth more than once-a finding determined by responses to the question, "Have you used this program in this booth before?” (Table 2).
We hope that this interactive, multimedia education program will encourage Veterans to implement hearing protective strategies in their daily lives. Author Saunders and colleagues at NCRAR are currently conducting a VA Rehabilitation Research and Development (RR\&D)-funded formal evaluation of the program. The study employs personal noise dosimeters to measure real-world noise exposure; ecological momentary assessments to measure realtime reported behavior; and a questionnaire to assess knowledge, attitudes, and behaviors of participants before and after they use the HLPP.

This HLPP will require wide dissemination and utilization if it is to reduce the prevalence of NIHL and tinnitus at all. As stated by Folmer et al. [9, p. 17], we hope to make this program available to all Veterans, military personnel, and other members of the public by providing access "through the internet and medical centers throughout the country. Most of the educational content of the program can be delivered via computer anywhere and does not require sound-attenuated enclosures.” Disseminating a computer-based HLPP through the Armed Forces could decrease the number of military personnel developing NIHL from noise exposure in training, combat, occupational, and recreational settings. In the long run, this would also decrease the number of Veterans experiencing and receiving compensation for hearing loss and tinnitus.

Robert L. Folmer, PhD; ${ }^{1-2 *}$ Gabrielle H. Saunders, PhD $;^{1-2}$ Serena M. Dann, AuD; ${ }^{1}$ Susan E. Griest, MPH; $;^{1-2}$ Edward Porsov, MS; $;^{2}$ Stephen A. Fausti, PhD; ${ }^{1-2}$ Marjorie R. Leek, PhD ${ }^{1-2}$

${ }^{1}$ NCRAR, Portland VA Medical Center, Portland, $\mathrm{OR} ;{ }^{2}$ Department of Otolaryngology, Oregon Health \& Science University, Portland, OR

*Email: Robert.Folmer@va.gov

\section{ACKNOWLEDGMENTS}

This project was funded by an award from the VA/DOD JIF. Additional support was provided by the VA RR\&D NCRAR at the Portland VA Medical Center. The authors thank the following individuals 
for their efforts on this project: Mike Lewis, Kim Hall, and the staff at OMSI; Carl and Sharon Jameson at Craftmaster Productions; Eleanor Cannady, John Dodier, and staff at Portland VAMC.

\section{REFERENCES}

1. Department of Veterans Affairs. Veterans Benefits Administration annual benefits report fiscal year 2010 Making a Difference [Internet]. [cited 2011 May 6]. Available from: http://www.vba.va.gov/reports/abr/ 2010 abr.pdf.

2. Fausti SA, Wilmington DJ, Helt PV, Helt WJ, Konrad-Martin D. Hearing health and care: the need for improved hearing loss prevention and hearing conservation practices. J Rehabil Res Dev. 2005;42(4 Suppl 2):45-62. [PMID:16470464] http://dx.doi.org/10.1682/JRRD.2005.02.0039

3. Saunders GH, Griest SE. Hearing loss in veterans and the need for hearing loss prevention programs. Noise Health. 2009;11(42):14-21. [PMID:19265249] http://dx.doi.org/10.4103/1463-1741.45308

4. Rosenstock I. Why people use health services. Milbank Mem Fund Q. 1966;44(3):94-127.

5. Zweig S, LeFevre M, Kruse J. The health belief model and attendance for prenatal care. Fam Pract Res J. 1988;8(1):32-41. [PMID:3239444]

6. Champion VL. The relationship of breast selfexamination to health belief model variables. Res Nurs Health. 1987;10(6):375-82. [PMID:3423309] http://dx.doi.org/10.1002/nur.4770100605

7. Pinto SL, Lively BT, Siganga W, Holiday-Goodman M, Kamm G. Using the Health Belief Model to test factors affecting patient retention in diabetes-related pharmaceutical care services. Res Social Adm Pharm. 2006;2(1):38-58. [PMID:17138500] http://dx.doi.org/10.1016/j.sapharm.2005.11.001

8. Lin WC, Ball C. Factors affecting the decision of nursing students in Taiwan to be vaccinated against hepatitis B infection. J Adv Nurs. 1997;25(4):709-18. [PMID:9104666] http://dx.doi.org/10.1046/j.13652648.1997.1997025709.x

9. Folmer RL, Saunders GH, Dann SM, Griest SE, Leek MR, Fausti SA. Development of a computer- based, multi-media hearing loss prevention education program for veterans and military personnel. Perspect Audiol. 2010;6(1):9-19.

http://dx.doi.org/10.1044/poa6.1.9

10. Kujawa SG, Liberman MC. Acceleration of agerelated hearing loss by early noise exposure: evidence of a misspent youth. J Neurosci. 2006;26(7): 2115-23. [PMID:16481444] http://dx.doi.org/10.1523/JNEUROSCI.4985$\underline{05.2006}$

11. Dirkx JM, Prenger SM. A guide for planning and implementing instruction for adults: a theme-based approach. San Francisco (CA): Jossey-Bass; 1997.

12. Echt KV. Designing web-based health information for older adults: visual considerations and design directives. In: Morrell RW, editor. Older adults, health information, and the world wide web. Mahwah (NJ): Erlbaum; 2002. p. 61-87.

13. Kirsch IS, Jungeblat A, Jenkins L, Kolstad A. Adult literacy in America. Washington (DC): National Center for Education Statistics, U.S. Department of Education; 1993.

14. Office of Disease Prevention and Health Promotion, U.S. Department of Health and Human Services. Healthy People Health Communication and Health Information Technology [Internet]. [cited 2011 May 9]. Available from: http://healthypeople.gov/2020/ topicsobjectives2020/overview.aspx?topicid=18.

15. Griest SE, Folmer RL, Martin WH. Effectiveness of "Dangerous Decibels," a school-based hearing loss prevention program. Am J Audiol. 2007;16(2):S165-81. [PMID:18056870] http://dx.doi.org/10.1044/1059-0889(2007/021)

This article and any supplementary material should be cited as follows:

Folmer RL, Saunders GH, Dann SM, Griest SE, Porsov E, Fausti SA, Leek MR. Computer-based hearing loss prevention education program for Veterans and military personnel. J Rehabil Res Dev. 2012;49(4): vii-xvi.

http://dx.doi.org/10.1682/JRRD.2012.02.0028

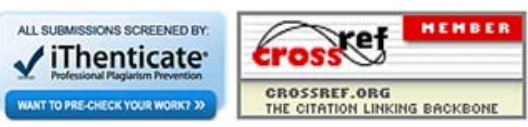


